\title{
Student Teaching Experience in Diverse Settings, White Racial Identity Development and Teacher Efficacy
}

\author{
Diane S. Bloom ${ }^{1} \&$ Terri Peters ${ }^{2}$ \\ ${ }^{1}$ College of Education, School of Curriculum and Teaching, Kean University, Toms River, USA \\ ${ }^{2}$ School of Education, Monmouth University, West Long Branch, USA \\ Correspondence: Diane S. Bloom, Kean-Ocean Campus, College of Education, School of Curriculum and \\ Teaching, Kean University, Toms River, NJ, 08754, USA. Tel: 1-732-229-0029. E-mail: dbloom@kean.edu
}

Received: June 27, 2012

doi:10.5539/jedp.v2n2p72

\author{
Accepted: July 12, 2012 \\ URL: http://dx.doi.org/10.5539/jedp.v2n2p72
}

\begin{abstract}
This study examined how diversity of field placement affected White student teachers' White racial identity (WRI) development, and the relationship between WRI and teacher efficacy. There was no change in WRI development regardless of placement; however, as the percentage of students of color in the placement increased, two subscales (instructional strategies, classroom management) of the Teacher Sense of Efficacy Scale (TSES) decreased. A negative correlation existed between WRI (Pseudo-Independence and Contact subscales of the White Racial Consciousness Development Scale-Revised) and subscales of the TSES. Results indicate that teacher preparation programs critically examine Whiteness and WRI as a construct.
\end{abstract}

Keywords: teacher efficacy, white racial identity, diversity, student teaching

\section{Introduction}

A significant number of teachers in the United States continue to be from European-American and middle or upper-class backgrounds, whereas the student population has become increasingly diverse (Howard, 2010). The National Center for Education Statistics (NCES, 2011) reported that almost half of the United States student population in 2008-2009 was non-White. The racial/ethnic distribution of full-time teachers shifted slightly between 1999-2000 and 2007-08, with only a slight increase in teachers who were Hispanic, and no significant changes in teachers who were Black (NCES, 2011).

Over the past few decades, researchers have begun to explore and understand the role that race plays in the teaching and learning process. Although unintentional, many White teachers "participate in the reproduction of racial inequality" (Hyland, 2005, p. 429) when teaching students of color. A large body of research has been devoted to helping teachers understand multiculturalism or culturally relevant teaching (Au, 2009; Haviland, 2008; Jones, 2006; Solomon, Portelli, Daniel, \& Campbell, 2005), and teacher education coursework on multiculturalism is common. However, less is known about how White future teachers construct their own White racial identity (WRI) or how WRI influences a teacher's efficacy for working with students of color. Past research (Buehler, Ruggles-Gere, Dallavis, \& Shaw-Haviland, 2009; Howard, 2010; Ruggles-Gere, Buehler, Dallavis, \& Shaw-Haviland, 2009) indicates that educators who are White and middle class face obstacles as educators of children in diverse settings. Therefore, the purpose of our study was to examine how diversity of field placement affected student teachers' White racial identity development, as well as the relationship between White racial identity and teacher efficacy (TE).

\subsection{Review of Literature}

The programs and processes that are in place at American universities to educate and prepare teachers for their chosen profession have been at the forefront of the United States Department of Education's focus on teacher quality and the goal to improve performance of urban students of color (Ogbu, 2003). To achieve this goal, educators have enacted several strategies including school restructuring, changes in assessment requirements, raising standards and mandating improvement in teacher qualifications. 


\subsubsection{Urban Students of Color}

Educational reform efforts have been created with the goal to reduce the achievement gap between suburban and urban students of color and their White peers (Howard, 2010; Kafer, 2001). These efforts, however, have not provided the mechanism for urban teachers to either improve the academic performance of students of color or the quality of their schools (Denbo \& Moore, 2002; Kafer, 2001). A qualified teacher is significant for improving student achievement, yet qualification alone is insufficient for enacting change in student performance (McKeachie \& Svinciki, 2006). Comer (2004) sees the role of the teacher as critically important; however, teachers must also be prepared to address the changing demographics of school communities and the academic and cultural needs of the diverse students they serve (Kyukendall, 2004; Rychly \& Graves, 2012; Tomlinson, 2001).

Mckinley (2010) presents five core causes for the achievement gap between students of color and their White student peers; he suggests reducing that gap by focusing on a "culturally responsive teaching" environment. These types of environments provide a supporting framework for content mastery that is related to students' home cultures, aligns to learning with positive interpersonal interactions, and employs diligent assessment practices (McKinley, 2010). Teachers who demonstrate "culturally responsive pedagogy" are caring teachers who have high expectations for all students and also provide constructive feedback to students (Rychly \& Graves, 2012). To become effective teachers of students of color, White teachers must reflect on their own world-views and continuously attempt to understand their students (Rychly \& Graves, 2012).

Many public school districts across the nation that serve at-risk students contend that various strategies and interventions have not adequately addressed school failure for a large number of these students (Rychly \& Graves, 2012; Welsh, 2010). For example, the standards movement articulated the need for all college-bound students to be fluent readers, writers, and mathematical thinkers; however the lack of clear standards for students not considered college-bound disproportionately hurt children of poverty, children of color, and children with disabilities, as teachers failed to identify them as college-bound students (Chenoweth, 2009).

\subsubsection{Teacher Misconceptions about Diverse Students}

Teachers must be prepared to address the changing demographics of school communities and the academic and cultural needs of the diverse students they serve (Kuykendall, 2004; Tomlinson, 2001). Teachers are often unaware of their biases and expectations of culturally diverse students, yet increased awareness of their unintentional behaviors and viewpoints can enhance student achievement (Rychly \& Graves, 2012). Educators should be consciously aware of the impact of labels such as culturally deprived, economically disadvantaged, and underprivileged on the student's self-image and potential (Kuykendall, 2004).

A common and problematic misconception held by some teachers is that students from culturally diverse backgrounds, particularly Blacks and Hispanics, are less capable academically (Bryan \& Atwater, 2002; Howard, 2010; Nieto, 2004). These misconceptions likely lead teachers to set lower academic goals and to rely more heavily on passive teaching methods (Science Education Research Center (SERC), 2009). Another misconception is that teachers should treat all students the same, regardless of class, gender, ethnicity, or race (Bryan \& Atwater, 2002; Howard, 2010). This "color blind" approach leads to teaching methods that do not consider the disparate educational and cultural backgrounds in an urban classroom (Howard, 2010; The Coalition of Schools Educating Boys of Color (TCOSEBOC), 2010). The preexisting knowledge base may differ considerably among diverse students (Manzo, 2010; Marzano, Pickering, \&Pollack, 2001; SERC, 2009).

\subsubsection{Teacher Efficacy: Impact on Student Learning}

Similar to the variability among the students they teach, teachers bring to their classrooms a world view about teaching and learning shaped through years of personal experience as learners within families, communities, and cultures. These teaching beliefs and practices shape the dynamics of student learning (Bryan \& Atwater, 2002), because teachers' beliefs translate into classroom instructional practice (Kuykendall, 2004) and also influence student learning (Bryan \& Atwater, 2002) and, in turn, teacher efficacy.

Teacher efficacy, an individual's belief that her or his teaching affects student learning (Raudenbush, Rowan, \& Cheong, 1992; Woolfolk Hoy \& Davis, 2006), has roots in seminal work by Bandura $(1977,1997)$. Bandura $(1977,1997)$ proposed that self-efficacy is a function of three interrelated factors: environmental, behavior, and internal personal factors (e.g., cognition, affective, biological). Individuals are thus products of the interaction between external influences, internal beliefs and current/past behavior. Self-efficacy impacts an individual's motivation, expectations, effort, emotions and persistence in situations of adversity; individuals with high efficacy will persevere when faced with challenging tasks (Maehr \& Pintrich, 1997; Pajares, 1997). 
Over a number of years, significant research has studied the impact of teacher efficacy on teacher quality and behavior. Research (Darling-Hammond, Chung, \& Frelow, 2002) has demonstrated that a teacher's sense of preparedness is the strongest predictor of teaching efficacy (Darling-Hammond et al., 2002; Tschannen-Moran, Woolfolk Hoy, \& Hoy, 1998), thus teacher efficacy is an important attribute to foster, because it can positively or negatively influence teacher behavior and, consequently, student learning and behavior.

Teacher efficacy is related to various positive classroom practices: (1) teachers' overall attitude toward teaching; (2) teachers' expectations of students; (3) willingness to persist with students who are struggling; (4) the ability to try various instructional techniques; and (5) student achievement (Gibson \& Dembo, 1984; Soodak \& Podell, 1997; Tschannen-Moran et al., 1998). Since teacher efficacy affects a teacher's ability to impact students in the classroom, a teacher's efficacy for working with students of color is paramount.

Many White teachers enter the profession without experience with diverse groups (Howard, 2010), and we questioned whether this lack of experience affects teacher efficacy and student outcomes. As noted by Siwatu (2011), preservice teachers felt better prepared to teach in suburban schools than urban schools. Siwatu (2011) also found that White teachers in suburban settings reported higher teacher efficacy for working with culturally and linguistically diverse students than when they are placed in urban settings. Conversely, other research found that student teachers placed in urban settings reported higher teacher efficacy at the end of the semester (Knoblauch \& Woolfolk Hoy, 2008).

We argue that unless individuals critically examine the factors that influence the outcomes of students of color, including historical factors that have oppressed certain groups, they cannot begin to improve the gap between White students and those of color. However, teachers avoid discussions about race due to discomfort (Haviland, 2008) or a belief that race is no longer an issue in the United States (Howard, 2010). In addition, a recent longitudinal study found that preservice teachers maintained their beliefs about working in diverse settings throughout their teacher preparation program (Gau \& Mager, 2011). White teachers must first examine their own beliefs and biases, as well as their students' perceptions of them as White teachers, before they can successfully work with students of color (Howard, 2010; Sleeter, 2001).

\subsubsection{White Racial Identity}

As teacher educators, we are committed to training preservice teachers to effectively work with all students. We struggle to understand how White preservice teachers navigate their urban field experiences. We also wonder if experiences in urban settings influence their understanding of their own background as well as their efficacy for working with students of color. The research on White racial identity provided a framework through which we began to understand the importance of White racial identity for promoting one's multicultural competence.

Helms' (1990) original theory of White racial identity (WRI) included six statuses, with higher levels representing more advanced understanding of one's Whiteness in the context of cross-cultural interactions. As empirical data were collected, however, Helms (2005) eliminated one of the statuses (immersion/emersion), yielding a model that consists of the following five statuses: (a) contact (unaware of the systemic presence of Whiteness, one's race, and the existence of racism); (b) disintegration (recognition of one's Whiteness, acknowledgement of racism, confusion and self-disorientation with respect to one's own Whiteness); (c) reintegration (idealization of being White, denigration of People of Color); (d) pseudo-independence (intellectual acceptance of one's race and racial privilege); and (e) autonomy (positive, antiracist White identity).

Higher levels of WRI represent more advanced understanding of one's Whiteness, and individuals at more advanced levels recognize injustices and are willing to take action to work for social justice (Helms, 2005). In contrast, individuals at lower level statuses (e.g., contact, disintegration) display an unawareness of White privilege and power or deny institutional racism. Moreover, certain statuses appear to predict racism (Pope-Davis \& Ottavi, 1994).

Haviland (2008) articulated the "silencing power" of Whiteness in education and explored how the interactional styles of White people in White-dominated educational settings impede movement toward progressive, anti-racist education. Her data from a yearlong qualitative research study uncovered strategies that participants used to insulate themselves from implication in social inequality. Use of these strategies stymied attempts at transformative multicultural education and thus functioned to reproduce, rather than challenge, the status quo of educational and social inequality (Haviland, 2008). Thus, Whites engage in "safe" dialogue and avoid discussions of race or racism, thereby perpetuating White privilege. Moreover, Whites who espouse "colorblindness" negate the impact of racism upon persons of color (Flores, Schwann, Dimas, Pasch, \& deGroat, 2010), preventing the development of their own racial identities. Prior research also shows that Whites in 
instructional settings are often reluctant to share their feelings about race and racism due to fear of appearing racist (Chick, Karis, \& Kernahan, 2009).

As indicated above, individuals avoid discussions of race and racism, and may adopt a "colorblind" approach to working with persons of color, behaviors that truncate their own WRI growth. Despite the frequent cultural mismatch between teachers and the students they serve, and the academic achievement gap between White students and those of color, a paucity of research has examined the influence of White teachers' White racial identity on their efficacy for working with students of color. Research demonstrates that teacher efficacy influences a teacher's ability to successfully work with all students (Tschannen-Moran et al., 1998), yet we found no empirical studies that examined the relationship between White student teachers' WRI and teacher efficacy.

\subsubsection{Research Questions}

We solely focused our study on White student teachers. Given the literature noted above, we desired to understand changes in these White preservice teachers' self-beliefs and perceptions about their abilities to impact students. We explored the inter-relationships among the diversity of student teaching placement, teacher efficacy, and teachers' WRI. Specifically, we examined whether: (1) there was a relationship between White racial identity statuses and teacher efficacy; (2) diversity of student teaching placement was related to White racial identity statuses and teacher efficacy; (3) those placed in more diverse settings showed changes in WRI; (4) those placed in non-diverse settings showed changes in WRI; and (5) diversity of placement affected changes in WRI development.

\section{Method}

\subsection{Participants}

We gathered information from participants enrolled in a teacher preparation program at a public university in the northeastern United States. Of 256 individuals who were enrolled in senior student teaching during the spring semester, 222 student teachers agreed to participate in the study. We were only interested in studying White student teachers for this study, so we only utilized data collected from individuals who self-identified as White. The final usable sample (completion of both pre and post measures) consisted of 146 White student teachers (91 females, 55 males), with an average age of 25.4 (range $=21-50)$. See Table 1 for demographic information for specific placements either categorized as high, low, or middle diverse school settings.

Table 1. Sample demographics for each type of school placement

\begin{tabular}{llll}
\hline \multicolumn{1}{c}{ Characteristic } & $\begin{array}{l}\text { Highly Diverse } \\
(\mathrm{n}=46)\end{array}$ & $\begin{array}{l}\text { Non-Diverse } \\
(\mathrm{n}=70)\end{array}$ & $\begin{array}{l}\text { Middle } \\
(\mathrm{n}=30)\end{array}$ \\
\hline Mean Age & 24.84 & 25.89 & 25.34 \\
Gender & $16 \mathrm{M}, 30 \mathrm{~F}$ & $28 \mathrm{M}, 42 \mathrm{~F}$ & $11 \mathrm{M}, 19 \mathrm{~F}$ \\
Licensure $_{\mathrm{a}}$ & & & \\
P-3 & 0 & 2.9 & 0 \\
K-5 & 21.7 & 14.5 & 6.9 \\
K-8 & 32.6 & 23.2 & 27.6 \\
K-12 & 41.3 & 52.2 & 62.1 \\
Other & 4.4 & 7.2 & 3.4 \\
\hline
\end{tabular}

Note. Middle $=$ Student teachers who were placed in a school that was neither highly diverse nor non-diverse; non-specified were those who did not report a school.

$\mathrm{a}=$ expressed in percentages

\subsection{Instruments}

\subsubsection{Teacher Sense of Efficacy Scale (TSES)}

The TSES long form (Tschannen-Moran \& Woolfolk-Hoy, 2001) consists of 24 nine-point likert items that ask respondents how much they believe they can influence student behavior $(1=$ not at all; $9=$ a great deal $)$ and consists of three subscales: (1) Instructional strategies; (2) student engagement; and (3) classroom management. 
Higher scores represent greater teacher efficacy. Past studies have shown high reliability of the TSES subscales, with alpha ranging from .87 to .91 (Tschannen-Moran \& Woolfolk-Hoy, 2001). For our sample, we also conducted an inter-item reliability analysis of the three TSES subscales and found high reliability for each subscale, ranging from .88 to .92 .

\subsubsection{White Racial Consciousness Development Scale, Revised (WRCDS-R)}

The WRCDS-R (Lee et al., 2007) is designed to measure White racial identity statuses that are aligned with Helms' (1990) theory of White racial identity development. The WRCDS-R consists of 40 five-point likert type items $(1=$ strongly disagree; $5=$ strongly agree) that reflect four White racial identity statuses: (1) Contact reflects naïve thoughts and ignorance about racial differences; (2) Reintegration represents feelings of anger and resentment toward ethnic minorities, and individuals who score high on this subscale see persons of Color as inferior to Whites; (3) higher scores on Pseudo Independence signify an increasing awareness and understanding of the impact of White dominance and privilege on racist attitudes and behaviors; and (4) Autonomy scores represent a non-racist White identity with appreciation of racial differences and similarities.

The current version of the WRCDS-R is the result of Lee et al.'s (2007) multi-stage approach to revising the White Racial Consciousness Development Scale (Claney \& Parker, 1989). After Lee et al. (2007) generated items, they conducted an exploratory factor analysis and subsequently eliminated several items and collapsed the disintegration items into the contact subscale. Next, Lee et al. (2007) performed a confirmatory factor analysis on the new 40-item WRCDS-R, using a sample of 168 White counselors and counselor educators $(76 \%$ female, $24 \%$ male) who were recruited through several national databases (e.g., Counselor Education Supervision Network, American Family Therapy Association) in the United States. Results demonstrated satisfactory reliability, with Cronbach's alpha coefficients at .81 for contact, .86 for reintegration, .84 for pseudo-independence, and .71 for autonomy. We also conducted a reliability analysis of the WRCDS-R using our sample, and results showed high inter-item reliability with alpha $=.82$ for Contact, .84 for Reintegration, .77 for Pseudo Independence, and .81 for Autonomy.

Lee et al. (2007) also sought to establish scale validity, so they gathered data from 402 White undergraduates (31\% male, $69 \%$ female) whom they recruited from campus classes and compared their scores to the counselor group noted above $(n=168)$. Findings indicated that the counselor group scored higher in the advanced statuses (pseudo-independence and autonomy) than undergraduate students, suggesting that the scale may be a valid instrument.

\subsubsection{Diversity of Placement}

On the demographic survey, participants were asked to record the name of their placement school, district, and city/town. From this information, the researchers used demographic information provided by the State to identify the percentage of White students in each school. For comparison purposes, placements were also coded into three categories: (1) highly diverse placements, schools where White students represented less than one-third of the student body; (2) non-diverse placements, schools where White students represented greater than two-thirds of the student body; and (3) average placements, schools that comprised the remainder of the placements (See Table 1).

\subsection{Research Design}

We utilized a causal-comparative design. Students who were placed in schools where the student population was predominantly White/Caucasian were compared to those who were placed in schools where the student population consisted primarily of students of color. The study examined how the diversity of placement affected White student teachers' WRI, as well as the relationship between WRI and TE.

\subsection{Procedures}

Prior to commencing our study, the research was approved by the university's Institutional Review Board and followed all requirements for ethical treatment of human subjects. At the beginning of the semester, researchers visited all class sections of student teaching seminars to obtain informed consent and distribute surveys. Students were informed about the study and its purposes, and those who wished to voluntarily participate completed the informed consent form, with the opportunity to ask questions before signing the form. The researcher collected the signed consent forms and then disseminated two likert surveys (TSES and WRCDS-R) and a demographic questionnaire. The researcher read the instructions, particularly indicating that only participants who self-identified as White/Caucasian were to fill out the WRCDS-R. Readings about the first year of teaching were included in the packet for those participants who either finished early or elected to not participate in the study. Upon completion of the student teaching experience at the end of the semester, White participants again 
completed the WRCDS-R and TSES, and students of color completed the TSES. We only used the data collected from student teachers who self-identified as White; all other data were securely stored but were not intended for use in our study.

\subsection{Data Analysis}

All data were entered into SPSS, and cases that were missing post-test data were eliminated. A Pearson product moment correlational analysis was used to examine the relationship between White racial identity statuses and teacher efficacy (research question 1), as well as the relationship between diversity of placement, White racial identity statuses, and teacher efficacy (research question 2). Paired sample t-tests were employed (research questions three and four) to investigate changes in White racial identity for individuals at specific sites (those placed in either highly diverse or non-diverse schools). For research question five, an analysis of covariance was conducted for each of the WRCDS-R sub-scales, using pretest scores on each sub-scale as the covariate to compare post test differences between student teachers placed in schools that served predominantly White students to those that primarily served Students of color.

\section{Results}

To address the first research question, a Pearson product moment correlational analysis examined the relationship between White racial identity statuses and teacher efficacy. The data indicated a significant negative correlation between scores on the contact subscale of the WRCDS-R and fcon all three subscales of the TSES (see Table 2). Contact is perceived to be a lower level of WRI development; therefore, as individuals reported greater naiveté or ignorance of racial differences (lower levels of WRI=higher scores on Contact), their beliefs about their ability to use effective instructional strategies, manage the classroom, and engage students decreased. The data also showed a significant negative correlation between scores on the Pseudo-Independence subscale of the WRCDS-R and scores on the Instructional Strategies subscale of the TSES. Pseudo-Independence represents greater awareness of the impact of White dominance and privilege on racist attitudes and behaviors; thus, as individuals reported greater awareness, their teacher efficacy regarding instructional strategies decreased.

Table 2. Intercorrelations for subscale scores on the WRCDS-R and TSES

\begin{tabular}{llllllll}
\hline & $\mathrm{N}$ & $\mathrm{SE}$ & $\mathrm{p}$ & $\mathrm{IS}$ & $\mathrm{p}$ & $\mathrm{CM}$ & $\mathrm{p}$ \\
\hline Contact & 146 & $-.24^{*}$ & .004 & $-.23^{*}$ & .007 & $-.21^{*}$ & .010 \\
Reintegration & 146 & -.12 & .153 & -.08 & .334 & -.02 & .843 \\
Pseudo-Independence & 146 & -.16 & .063 & $-.18^{*}$ & .030 & -.15 & .070 \\
Autonomy & 146 & .16 & .054 & .14 & .078 & .03 & .669
\end{tabular}

Description: The four subscales of the White Racial Consciousness Development Scale-Revised (WRCDS-R) include Contact, Reintegration, Pseudo-Independence, and Autonomy; Contact and Reintegration are viewed as lower level statuses (Helms, 1990). The three subscales of the Teachers Sense of Efficacy Scale (TSES) include Student Engagement (SE), Instructional Strategies (IS), and Classroom Management (CM) (Tschannen-Moran et al. 1998).

$* \mathrm{p}<.05$.

Second, a correlational analysis was used to investigate the relationship between White racial identity statuses, diversity of field placements (measured by the percentage of White students in the school) and teacher efficacy. Results showed a significant positive correlation between the diversity of the school and two subscales of the TSES: Instructional Strategies and Classroom Management (see Table 3). Thus, as the percentage of White students in the school increased, teacher efficacy regarding classroom management and instructional strategies increased. We found no significant correlation between subscale scores on the WRCDS-R and diversity of field placements. 
Table 3. Correlations between diversity of school ${ }^{\mathrm{a}}$ and subscales of the TSES

\begin{tabular}{llll}
\hline & $\mathrm{N}$ & $\mathrm{r}$ & Sig. \\
\hline Student Engagement & 146 & .13 & .11 \\
Instructional Strategies & 146 & $.17^{*}$ & .04 \\
Classroom Management & 146 & $.21^{*}$ & .01
\end{tabular}

Description: ${ }^{\mathrm{a} D i v e r s i t y ~ o f ~ S c h o o l ~ i s ~ d e f i n e d ~ a s ~ t h e ~ p e r c e n t a g e ~ o f ~ W h i t e ~ s t u d e n t s ~ e n r o l l e d ~ i n ~ t h e ~ s c h o o l . ~}$

*Correlation is significant $(\mathrm{p}<.05)$.

To address research questions three and four, paired sample t-tests examined changes in the four subscales of the WRCDS-R for individuals placed in either highly diverse or non-diverse schools. The results indicated that neither group experienced significant changes on any of the WRCDS-R subscales (see Table 4).

Table 4. Changes in WRCDS-R for student teachers in either Highly Diverse (HD) or Non-Diverse (ND) schools

\begin{tabular}{|c|c|c|c|c|c|c|c|c|c|c|}
\hline & & \multicolumn{2}{|c|}{$\underline{\text { Time } 1}$} & \multicolumn{2}{|c|}{$\underline{\text { Time } 2}$} & \multirow[b]{2}{*}{$\mathrm{t}$} & \multirow[b]{2}{*}{ df } & \multirow[b]{2}{*}{$\mathrm{p}$} & \multicolumn{2}{|c|}{$95 \% \mathrm{CI}$} \\
\hline & & M & SD & M & SD & & & & LL & UL \\
\hline \multicolumn{11}{|l|}{ Contact } \\
\hline & HD & 14.02 & 5.58 & 14.70 & 5.45 & 1.05 & 43 & .30 & -1.98 & .62 \\
\hline & ND & 17.01 & 6.92 & 17.23 & 6.89 & .37 & 68 & .71 & -1.39 & .95 \\
\hline \multicolumn{11}{|c|}{ Reintegration } \\
\hline & HD & 39.05 & 8.06 & 38.95 & 9.01 & .10 & 37 & .92 & -2.02 & 2.23 \\
\hline & ND & 40.63 & 9.38 & 40.85 & 8.98 & 1.02 & 67 & .31 & -2.43 & .79 \\
\hline \multicolumn{11}{|c|}{ Pseudo-Independence } \\
\hline & HD & 20.40 & 4.18 & 19.40 & 5.09 & 1.50 & 39 & .14 & -.35 & 2.35 \\
\hline & ND & 18.88 & 4.02 & 18.10 & 5.00 & 1.44 & 66 & .15 & -.30 & 1.85 \\
\hline \multicolumn{11}{|c|}{ Autonomy } \\
\hline & HD & 32.36 & 7.53 & 32.05 & 7.52 & .45 & 41 & .65 & -1.07 & 1.14 \\
\hline & ND & 30.90 & 6.81 & 29.93 & 7.02 & 1.69 & 68 & .10 & -.17 & 2.16 \\
\hline
\end{tabular}

Description: $\mathrm{CI}=$ confidence interval; $\mathrm{LL}=$ lower limit; $\mathrm{UL}=$ upper limit.

Finally, an analysis of covariance was conducted for each of the four WRCDS-R subscales to compare post-test differences between those placed in predominantly White schools to those who were placed in more diverse settings. A separate ANCOVA was utilized for each of the four subscales, using the specific pre-test as the covariate. This provided a robust comparison, controlling for initial differences on the subscale pre-test. The results indicated no significant differences on any of the subscales (see Table 5). 
Table 5. Differences between student teachers placed in Highly Diverse (HD) or Non-Diverse (ND) schools onWRCDS-R subscores, controlling for pretest scores

\begin{tabular}{|c|c|c|c|c|c|}
\hline WRCDS-R & Source & $\mathrm{df}$ & Mean Square & $\mathrm{F}$ & Sig \\
\hline \multicolumn{6}{|l|}{ Contact } \\
\hline & Intercept 1 & & & & \\
\hline & Pre-test 1 & & & & \\
\hline & School Type & 1 & 10.02 & .51 & .48 \\
\hline & Error & 110 & 19.62 & & \\
\hline \multicolumn{6}{|c|}{ Reintegration } \\
\hline & Intercept 1 & & & & \\
\hline & Pre-test 1 & & & & \\
\hline & School Type & 1 & 5.65 & .20 & .66 \\
\hline & Error & 101 & 18.63 & & \\
\hline \multicolumn{6}{|c|}{ Pseudo-Independence } \\
\hline & Intercept 1 & & & & \\
\hline & Pre-test 1 & & & & \\
\hline & School Type & 1 & 9.47 & .46 & .50 \\
\hline & Error & 101 & 10.43 & & \\
\hline \multicolumn{6}{|l|}{ Autonomy } \\
\hline & Intercept 1 & & & & \\
\hline & Pre-test 1 & & & & \\
\hline & School Type & 1 & 28.82 & 1.34 & .25 \\
\hline & Error & 105 & 21.51 & & \\
\hline
\end{tabular}

Description: Pre-tests on the subscales served as covariates. School type consists of 2 levels: HD and ND.

\section{Discussion}

Schools of education across the United States are faced with the challenges of training teachers who are predominantly White to effectively work in schools with a large number of students of color. Unfortunately, many educators who prepare future teachers advocate a color-blind approach for working with students of color, despite ample research that supports the need for developing lessons based upon student background (Banks, 2007). Moreover, teachers who are specifically trained to work with culturally diverse students have greater levels of teacher efficacy to work with those students (Siwatu \& Starker, 2010). Universities and colleges fall short in their attempts to address this, however, by providing either a single course or a single textbook chapter devoted to multiculturalism for the entire teacher preparation program. According to Banks (2007), having a formal curriculum and multicultural teaching materials are necessary, but not sufficient; materials are going to be highly ineffective by teachers who have naive, ignorant, and/or negative attitudes toward these diverse groups.

Surprisingly, the results of our study indicate that specific aspects of White racial identity, as well as diversity of field experiences, were related to student teachers' self efficacy. For example, as their awareness of the impact of White dominance and privilege on the establishment of inequities in society increased (score on Pseudo Independence), their teacher efficacy decreased. As White preservice teachers became more aware of the challenges facing students of color, perhaps they became more self-conscious and unsure of their ability to teach these students. Increased awareness and knowledge may lead to discomfort, which could also explain lower levels of teacher efficacy. Therefore, mere exposure without adequate training to work in diverse settings is insufficient to promote competence for teaching in diverse classrooms.

Our study presented findings at the culmination of 15 weeks of student teaching. We found that as the percentage of students of color enrolled in a school increased, preservice teachers reported lower levels of efficacy to implement both effective instructional strategies and classroom management techniques. We wondered if the 
strategies these teachers had learned and practiced in a prior setting were ineffective for working with more culturally diverse students. Alternatively, is it possible that teachers' perceptions of students of color correspond with lower expectations of their own abilities to work with these students?

Our research indicated that greater levels of ignorance about racial differences (Contact subscale of the WRCDS-R) also had deleterious effects on teacher efficacy, as indicated by its negative correlation with all three subscales of teacher efficacy. Thus, a color-blind approach apparently will not promote confidence for implementing pedagogical strategies with students of color. Individuals are often unaware of issues of race and racism due to the communities in which they live (Solomon et al., 2005), indicating that individuals need more cross-cultural contact to foster WRI development (Valli, 1995). Although contact may be a prerequisite for WRI development, our study did not find any differences in WRI development between student teachers who taught in either schools with a high or a low percentage of students of color. In addition, when investigating changes in WRI growth, neither group of student teachers (those placed in diverse or non-diverse settings) significantly changed over the course of the semester, suggesting that more than cross-cultural exposure is necessary to promote WRI growth.

Our study found that student teachers maintained their initial WRI beliefs and experienced lower levels of self-efficacy when teaching in diverse school settings where the dominant culture was different from their own. As noted by Pollock, Deckman, Mira, and Shalaby (2010), preservice teachers reported the need to come to terms with their own White privilege and guilt before they could develop specific classroom skills for working with students of color. Indeed, teacher educators should engage in conversations about race, racial identity, and race-related issues of privilege and power, topics that frequently are avoided in situations wherein participants are predominantly White (Pennington, 2007).

As noted by McKay (2010), critical pedagogy implies that educators must continuously question the dominant culture's perspective and consider alternative perspectives for working with diverse groups. Thus, open dialogue about educational practices and their impact on race are necessary to impact outcomes for students of color. Since the student population in public schools across the United States is becoming increasingly diverse, educators need to consider the inclusion of WRI in the training of future teachers.

Educators should consider reforms and strategies for change that not only embrace the teacher but also the students and their families (Banks, 2007). This approach will enable educators to better relate to and understand student behavior, thereby participating in "prejudice reduction". Banks expresses concern that children "come to school with many negative attitudes toward and misconceptions about different racial and ethnic groups" (Banks, 2007, p. 21) that influence cross-cultural interactions and academic success. Establishing positive images, role models, and sensitive multiethnic materials within a sequential curriculum may be one aspect that will foster student success. This approach can be addressed within teacher preparation programs. However, teacher training must move beyond the provision of multicultural materials and address the role of a teacher's race, as well as teachers' conceptions of classroom management, instructional strategies, and student engagement (Banks, 2001). Through dialogue with students and families from diverse backgrounds, teachers can reflect on their own beliefs, identify biases, and attempt to teach and manage a sensitive, efficient, effective classroom.

\section{Conclusion}

As perhaps the first empirical study to examine the relationship between White racial identity and teacher efficacy, and given the paucity of research on Whiteness in general, our study extends the current body of literature. Given the impact of teacher efficacy on student performance, understanding the relationship to White racial identity is imperative and warrants further study. Also, considering the demographics of the teaching force in the United States, cultural competence is paramount, and our study attempts to uncover the role of White racial identity in the development of teacher efficacy for working with students of color.

We found that student teachers who were placed in settings with larger numbers of students of color had lower levels of teacher efficacy. As noted by Wihak and Meral (2007), contact is a prerequisite for White racial identity development, but mere contact alone is insufficient for promoting positive White racial identity growth, as White individuals resist ideas of White privilege and power (LaDuke, 2009). Moreover, instructors who attempt to discuss these issues in multicultural courses report that students will attempt to change the subject or disengage from discussions of race (LaDuke, 2009).

We believe that schools of education must move beyond merely placing students in diverse classrooms. Instead, programs need to embed content about Whiteness throughout the curriculum and engage in dialogue about Whiteness issues, acknowledging and discussing personal bias and how biases influence teachers' misconceptions and assumptions about teaching and student learning. Addressing WRI in teacher training could 
increase White prospective teachers' awareness of their racial biases, the impact of these biases on their behavior, along with the unintended consequences of those behaviors (Castillo et al., 2006; Sue, et al., 2008). Educating White teachers regarding White racial identity, along with ample experiences in diverse settings, coupled with reflective discussions in accompanying seminars, may induce positive WRI development and, ultimately, positive classroom experiences for their students of color.

We acknowledge the limitations inherent in correlational research, but also recognize the implications of our study for future research. More controlled studies are warranted to investigate pre-post changes in WRI and teacher efficacy following training that focuses on cross-cultural communication and experience along with teachers' critical examination of their own beliefs and biases.

\section{References}

$\mathrm{Au}, \mathrm{W}$. (2009). Rethinking multicultural education: Teaching for racial and cultural justice. Milwaukee, WI: Rethinking Schools, Ltd.

Bandura, A. (1977). Self-efficacy: Toward a unifying theory of behavioral change. Psychological Review, 84, 191-215. http://dx.doi.org/10.1037/0033-295X.84.2.191

Bandura, A. (1997). Self-efficacy: The exercise of control. New York: Freeman.

Banks, J. A. (2001). Approaches to Multicultural Curriculum Reform. In J. A. Banks \& C .A. M. Banks (Eds.), Multicultural Education: Issues and Perspectives (4th ed., pp.225-246). New York: John Wiley \& Sons.

Banks, J. A. (Ed.). (2007). Multicultural education: Characteristics and goals. In J. \& C. Banks (Ed.) Multicultural Education (6th ed., pp. 3-30). Hoboken, NJ: John Wiley \& Sons.

Bryan, L., \& Atwater, M. (2002). Teacher beliefs and cultural models. Science Education, 86(6), 821-839. http://dx.doi.org/10.1002/sce.10043

Buehler, J., Ruggles-Gere, A., Dallavis, C., \& Shaw-Haviland, V. (2009). Normalizing the fraughtness: How emotion, race, and school context complicate cultural competence. Journal of Teacher Education, 60(4), 408-418. http://dx.doi.org/10.1177/0022487109339905

Castillo, L. G., Conoley, C. W., King, J., Rollins, D., Rivera, S., \& Veve, M. (2006). Predictors of racial prejudice in White American counseling students. Journal of Multicultural Counseling and Development, 34, 15-26. http://dx.doi.org/10.1002/j.2161-1912.2006.tb00023.x

Chenoweth, K. (2009). How it's being done: Urgent lessons from unexpected schools. Cambridge, MA: Harvard Education Press.

Chick, N. Karis, T., \& Kernahan, C. (2009). Learning from their own learning: How metacognitive and meta-affective reflections enhance learning in race-related courses. International Journal for the Scholarship of Teaching and Learning, 3, 1-28. Retrieved from http://academics.georgiasouthern.edu/ijsotl//v3n1.html.

Claney, D., \& Parker, W. M. (1989). Assessing White racial consciousness and perceived comfort with Black individuals: A preliminary study. Journal of Counseling \& Development, 67, 449-451. http://dx.doi.org/10.1002/j.1556-6676.1989.tb02114.x

Comer, J. P. (2004). Leave no child behind: Preparing today's youth for tomorrow's world. London: Yale University Press.

Darling-Hammond, L., Chung, R., \& Frelow, F. (2002). Variation in teacher preparation: How well do different pathways prepare teachers to teach? Journal of Teacher Education, 53(4), 286-302. http://dx.doi.org/10.1177/0022487102053004002

Denbo, S., L., \& Jones, V. (2002). Foreword. In More Beaulieu (ed.), Improving schools for African American students. Springfield, IL: Charles C. Thomas.

Flores, E., Schwann, J. M., Dimas, J. M., Pasch, L. A., \& de Groat, C. L. (2010). Perceived racial/ethnic discrimination, posttraumatic stress symptoms, and health risk behaviors among Mexican American adolescents. Journal of Counseling Psychology, 57(3), 264-273. http://dx.doi.org/10.1037/a0020026

Gao, W., \& Mager, G. (2011). Enhancing preservice teachers' sense of efficacy and attitudes toward school diversity through preparation: A case of one U.S. inclusive teacher education program. International Journal of Special Education, 26(2), 92-107.

Gibson, S., \& Dembo, M. (1984). Teacher efficacy: A construct validation. Journal of Educational Psychology, 
76(4), 569-582. http://dx.doi.org/10.1037/0022-0663.76.4.569

Haviland, V. S. (2008). Things get glossed over: Rearticulating the silencing power of whiteness in education. Journal of Teacher Education, 59(40), 40-54. http://dx.doi.org/10.1177/0022487107310751

Helms, J. E. (Ed.). (1990). Black and White racial identity: Theory, research, and practice. Westport, CT: Greenwood Press.

Helms, J. E. (2005). Challenging some misuses of reliability coefficients as reflected in evaluation of the White Racial Identity Attitude Scale (WRIAS). In R. T. Carter (Ed.), Handbook of racial-cultural psychology and counseling: Theory and research (Vol. 1, pp. 360-390). New York, Wiley.

Howard, T. C. (2010). Why race and culture matter in schools: Closing the achievement gap in America's classrooms. New York, NY: Teachers College Press.

Hyland, N. E. (2005). Being a good teacher of Black students? White teachers and unintentional racism. Curriculum Inquiry, 35(4), 429-459. http://dx.doi.org/10.1111/j.1467-873X.2005.00336.x

Jones, J. M. (2006). The psychology of multiculturalism in schools: A primer for practice, training, and research. Bethesda, MD: National Association of School Psychologists.

Kafer, K. (2001). A failing grade for s.1, the senate education committee bill. Retrieved from http://www.heritage.org/Research/Education/BG1433.cfm.

Knoblauch, D., \& Woolfolk Hoy, A. (2008). "Maybe I can teach those kids.” The influence of contextual factors on student teachers' efficacy beliefs. Teaching and Teacher Education, 24(1), 166-179. http://dx.doi.org/10.1016/j.tate.2007.05.005

Kuykendall, C. (2004). From rage to hope: Strategies for reclaiming black \& hispanic students (2nd ed.). Bloomington, IN: National Education Service.

LaDuke, A. (2009). Resistance and renegotiation: Preservice teachers interactions with and reactions to multicultural education course content. Multicultural Education, 16(3), 37-44.

Lee, S. M., Puig, A., Pasquarella-Daley, L., Denny, G., Rai, A. A., Dallape, A., \& Parker, W. M. (2007). Revising the White racial consciousness development scale. Measurement and Evaluation in Counseling and Development, 39, 194-208.

Maehr, M., \& Pintrich, P. R. (1997). Advances in motivation and achievement. Greenwich, CT: JAI Press.

Manzo, K. K. (2010). Spotlight on differentiated instruction: The personal approach. Education Week Teacher Professional Development Sourcebook. Retrieved from http://www.edweek.org/products/spotlight/05112020spotlighton Differentiated Instruction.pdf

Marzano, R., Pickering, D. J., \& Pollack, J. E. (2001). Classroom instruction that works: Research based strategies for increasing student achievement. Alexandria, VA: ASCD.

McKay, C. L. (2010). Community education and critical race praxis: The power of voice. Educational Foundations, Winter-Spring, 25-38.

McKeachie, W. J., \& Svinicki, M. (2006). Teaching tips: strategies, research, and theory for college and university teachers. Boston, MA: Houghton Mifflin Company.

McKinley, J. (2010). Raising Black students' achievement through culturally responsive teaching. Alexandria, VA: ASCD.

National Center for Education Statistics (2011). The condition of education 2011. Washington, DC: The United States Department of Education.

National School Board Foundation, (2002). Leadership matters: transforming urban schools boards. Retrieved from http://www.nsbf.org/report/index.html.

Nieto, S. (2004). Affirming diversity: The sociopolitical context of multicultural education. Boston, MA: person Allyn \& Bacon.

Ogbu, J. V. (2003). Black American students in an affluent suburb: A study of academic disengagement. Mahway, NJ: Lawrence Erlbaum Associates, Inc.

Pajares, F. (1997). Current directions in self-efficacy research. In M. Maehr \& P. R. Pintrich (Eds.), Advances in motivation and achievement (Vol. 10, pp. 1-49). Greenwich, CT: JAI Press. 
Pennington, J. L. (2007). Silence in the classroom/whispers in the halls: Autoethnography as pedagogy in White pre-service teacher education. Race Ethnicity and Education, 10(1), 93-113. http://dx.doi.org/10.1080/13613320601100393

Pollock, M., Deckman, S., Mira, M., \& Shalaby, C. (2010). "But what can I do?" Three necessary tensions in teaching teachers about race. Journal of Teacher Education, 61(3), 211-224. http://dx.doi.org/10.1177/0022487109354089

Pope-Davis, D. B., \& Ottavi, T. M. (1994). Examining the association between self-reported multicultural counseling competencies and demographic and educational variables among counselors. Journal of Counseling and Development, 72, 651-654. http://dx.doi.org/10.1002/j.1556-6676.1994.tb01697.x

Raudenbush, S., Rowen,B., \& Cheong, Y. (1992). Contextual effects on the self-perceived efficacy of high school teachers. Sociology of Education, 65, 150-167. http://dx.doi.org/10.2307/2112680

Ruggles-Gere, A., Buehler, J., Dallavis, C., \& Shaw-Haviland, V. (2009). A visibility project: Learning to see how preservice teachers take up culturally responsive pedagogy. American Educational Research Journal, 46(3), 816-852. http://dx.doi.org/10.3102/0002831209333182

Rychly, L., \& Graves, E. (2012). Teacher characteristics for culturally responsive pedagogy. Multicultural Perspectives, 14(1), 44-49. http://dx.doi.org/10.1080/15210960.2012.646853

Science Education Resource Center (SERC). (2009). How to engage and support urban students. Retrieved fromhttp://serc.carlton.edu/intrgeo/urban/how.html

Siwatu, K. O. (2011). Preservice teachers' sense of preparedness and self-efficacy to teach in America's urban and suburban schools: Does context matter? Teaching and Teacher Education, 27, 357-365. http://dx.doi.org/10.1016/j.tate.2010.09.004

Siwatu, K. O., \& Starker, T. V. (2010). Predicting preservice teachers' self-efficacy to resolve a cultural conflict involving an African American student. Multicultural Perspectives, 12(1), 10-17. http://dx.doi.org/10.1080/15210961003641302

Sleeter, C. E. (2001). Preparing teachers for culturally diverse schools: Research and the overwhelming presence of Whiteness. Journal of Teacher Education, 52(2), 94-106. http://dx.doi.org/10.1177/0022487101052002002

Solomon, R. P., Portelli, J. P., Daniel, B. J., \& Campbell, A. (2005). The discourse of denial: How white teacher candidates construct race, racism and "white privilege". Race, Ethnicity and Education, 8(2), 147-169.

Soodak, L., \& Podell, D. (1996). Efficacy and experience: Perceptions of efficacy among preservice and practicing teachers. Journal of Research and Development in Education, 30, 214- 221.

Sue, D. W., Nadal, K. L., Capodilupo, C. M., Lin, A. I., Rivera, D. P., \& Torino, G. C. (2008). Racial Microaggressions against Black Americans: Implications for counseling. Journal of Counseling and Development, 86(3), 330-338. http://dx.doi.org/10.1002/j.1556-6678.2008.tb00517.x

Tomlinson, C. A. (2001). How to differentiate instruction in mixed ability classrooms (2nd ed.). Alexandria, VA: ASCD.

Tschannen-Moran, M., \& Woolfok-Hoy, A. (2001). Teacher efficacy: capturing an elusive construct. Teaching and Teacher Education, 17, 783-805. http://dx.doi.org/10.1016/S0742-051X(01)00036-1

Tschannen-Moran, M., Hoy, A. W., \& Hoy, W. K. (1998). Teacher efficacy: Its meaning and measure. Review of Educational Research, 68, 202-248.

The Coalition of Schools Educating Boys of Color (TCOSEBOC). (2010). Standards and promises practices for schools educating boys of color: A self-assessment tool. Metropolitan Center: New York. Retreived from http://www.successfulforblackboys.org/2/post/2010/6/

Valli, L. (1995). The dilemma of race: Learning to be color blind and color conscious. Journal of Teacher Education, 46(2), 120-129. http://dx.doi.org/10.1177/0022487195046002006

Welsh, P. (2010, March 19). At T.C. Williams High School, a "low achieving' label is a wakeup call. Retrieved from http://www.washingtonpost.com/wpdyn/content/article/2010/03/19/AR2010031901362_pf.html

Wihak, C., \& Meral, N. (2007). Adaptations of professional ethics among counselors living and working in a remote Native Canadian community. Journal of Multicultural Counselor Development, 35(3), 169-180. http://dx.doi.org/10.1002/j.2161-1912.2007.tb00058.x 
Woolfolk Hoy, A., \& Davis, H. (2006). Teachers' sense of efficacy and adolescent achievement. In F. Pajares \& T. Urdan (Eds.), Self efficacy beliefs of adolescents (pp. 117-137). Greenwich, CT: Information Age Publishing. 